\title{
Ethnic differences in prevalence and risk factors for hypertension in the Suriname Health Study: a cross sectional population study
}

Ingrid S. K. Krishnadath ${ }^{1 *}$, Vincent W. V. Jaddoe ${ }^{3,4}$, Lenny M. Nahar-van Venrooij ${ }^{1}$ and Jerry R. Toelsie ${ }^{2}$

\begin{abstract}
Background: Limited information is available about the prevalence, ethnic disparities, and risk factors of hypertension within developing countries. We used data from a nationwide study on non-communicable disease (NCD) risk factors to estimate, explore, and compare the prevalence of hypertension overall and in subgroups of risk factors among different ethnic groups in Suriname.

Method: The Suriname Health Study used the World Health Organization Steps design to select respondents with a stratified multistage cluster sample of households. The overall and ethnic specific prevalences of hypertension were calculated in general and in subgroups of sex, age, marital status, educational level, income status, employment, smoking status, residence, physical activity, body mass index (BMI), and waist circumference (WC). Differences in the prevalence between ethnic subgroups were assessed using the Chi-square test. We used several adjustment models to explore whether the observed ethnic differences were explained by biological, demographic, lifestyle, or anthropometric risk factors.

Results: The prevalence of hypertension was $26.2 \%$ (95 \% confidence interval $25.1 \%-27.4 \%$ ). Men had higher mean values for systolic and diastolic blood pressure compared to women. Blood pressure increased with age. The prevalence was highest for Creole, Hindustani, and Javanese and lowest for Amerindians, Mixed, and Maroons. Differences between ethnic groups were measured in the prevalence of hypertension in subcategories of sex, marital status, education, income, smoking, physical activity, and BMI. The major difference in association of ethnic groups with hypertension was between Hindustani and Amerindians.

Conclusion: The prevalence of hypertension in Suriname was in the range of developing countries. The highest prevalence was found in Creoles, Hindustani, and Javanese. Differences in the prevalence of hypertension were observed between ethnic subgroups with biological, demographic, lifestyle, and anthropometric risk factors. These findings emphasize the need for ethnic-specific research and prevention and intervention programs.
\end{abstract}

Keywords: Amerindian, Ethnicity, Hypertension, Risk factors, Suriname

\footnotetext{
* Correspondence: Ingrid.Krishnadath@uvs.edu

${ }^{1}$ Department of Public Health, Faculty of Medical Sciences, Anton de Kom

University of Suriname, Paramaribo, Suriname

Full list of author information is available at the end of the article
} 


\section{Background}

Hypertension is the fourth-largest contributor to premature death in industrialized countries and the seventh in developing countries [1-3]. The increasing prevalence of hypertension in developing countries could be the result of factors like urbanization, population aging, unhealthy dietary habits, and social stress [4]. In several industrialized countries, ethnic differences in the prevalence of hypertension and its risk factors have been described extensively [5-17]. In contrast, in developing countries less research has been conducted. Studies reported higher prevalence of hypertension among adults from African descent followed by those of Asian or Hispanic descent, as compared to Caucasians [7-9, 18-20].

The Republic of Suriname, located on the northeast of South America, is an upper-middle income country with a multi-ethnic and multicultural population, with inhabitants of mainly Indian, African, and Indonesian descent. In this country, cardiovascular disease has been the main cause of mortality for decades in each ethnic group [21]. However, information about the prevalence and risk factors of hypertension among these different groups is limited. So far, a study from 2001, limited to three coastal districts, reported a hypertension prevalence of $33 \%$ in adults between the ages of 18-55 years [22]. Of all participants, $70 \%$ were physically inactive, $30 \%$ smoked, $20 \%$ were obese, and $15 \%$ had high total cholesterol levels. In adults, the highest prevalence of hypertension has been observed in Creoles [22]. In adolescents, hypertension was measured more frequently in Hindustani and Javanese [23].

We used data from a nationwide study on noncommunicable disease (NCD) risk factors [24], to estimate, explore, and compare the prevalence of hypertension overall and in subgroups of biological, demographic, lifestyle, and anthropometric risk factors among different ethnic groups in Suriname.

\section{Methods \\ Design}

We used data from the Suriname Health Study, the first nationwide study on NCD risk factors [24], which was designed according to World Health Organization (WHO) Steps guidelines [25]. The Ethics Committee of the Ministry of Health in Suriname (Commissie mensgebonden wetenschappelijk onderzoek (ref: VG 004-2013)) approved this research. Suriname has approximately 550,000 inhabitants, categorized into $15.7 \%$ Creole (descendants of African plantation slaves), $27.4 \%$ Hindustani (people of Indian heritage), 13.7 \% Javanese (descendants from Indonesians), $21.7 \%$ Maroon (descendants of African refugees who escaped slavery and formed independent settlements in the hinterland), $13.4 \%$ mixed, $7.6 \%$ others, including Amerindians (original inhabitants), and $0.6 \%$ unknown [26]. Because of financial restraints and the extended survey area in Suriname we used a stratified multistage cluster sample of households to select respondents between March and September 2013 for this study [24]. The strata were based on the geographic location of the sampling units in the various districts. The Primary Sampling Unit (PSU) of the sampling frame consists of the 10 districts of Suriname. The Secondary Sampling Units (SSU) consisted of 101 randomly selected enumeration areas (EAs) in nine districts and four randomly selected village areas in a remote tenth district, Sipaliwini. The SSU was divided into 343 clusters, which were selected randomly within the enumeration areas. Except for the 16 clusters in district Sipaliwini, each cluster contained 25 households. The clusters in Sipaliwini contained 40 households, due to the large cost of transportation to the isolated villages in the tropical rainforest. In the selected households, the respondent was identified using the Kish method based on gender and age [27]. In total, 7493 individuals between the age of 15 and 65 years were invited to participate in the study. The response rate was $76.8 \%$, resulting in 5748 participants. The percentage of missing data was relatively small (1.1 \%) for most variables except for income status (30.2\%) [24].

\section{Main outcome}

We measured blood pressure three times with the Omron HEM-780 blood-pressure monitor.

Before measurements, respondents were seated (legs uncrossed) to rest for at least $15 \mathrm{~min}$. Measurements were repeated at a time interval of three minutes. The mean of the last two measurements was used to calculate the blood pressure of the participant [28]. Hypertension was defined as a systolic blood pressure $\geq 140 \mathrm{~mm}$ $\mathrm{Hg}$, diastolic pressure $\geq 90 \mathrm{~mm} \mathrm{Hg}$, or current treatment with antihypertensive medication [29].

Hypertensive respondents were considered aware of their condition when previously diagnosed and using antihypertensive medication. Additionally, they were considered to have their hypertensive condition under control when they used antihypertensive medication and had measurements of $<140 \mathrm{~mm} \mathrm{Hg}$ for systolic blood pressure and $<90 \mathrm{~mm} \mathrm{Hg}$ for diastolic blood pressure.

\section{Risk factors}

We used interviews and hands-on measurements to collect information. Trained interviewers used an adapted WHO steps questionnaire to collect demographic and lifestyle information. Participants were categorized into a specific ethnic group if at least three of four grandparents were of this ethnicity. Anybody else was considered to be of mixed ethnicity. Next to ethnicity, we considered biological factors like sex and age; demographic 
factors like marital status, educational level, income status, employment, and residence (stratified into urban, rural coastal, and rural interior areas); lifestyle factors like cigarette smoking and physical activity (in Metabolic Equivalent of Task (MET) minutes); and anthropometric factors like body mass index (BMI) and waist circumference (WC) as risk factors for hypertension. The Global Physical Activity Questionnaire (GPAQ) was used to measure physical activity. All measurements were carried out as described in Part 3 "Training and Practical guides" of the WHO steps manual with the recommended equipment [28]. Height was measured with the Seca 213 stand-alone stadiometer, and WC was determined with the Seca 201 measuring tapes. The respondents were weighed with the Tanita HS302 solar scale. BMI was classified in the categories; <23, 23-25, 25-27.5, 27.5-30 and $30+$, taking into account the WHO ethnicspecific cutoff points for overweight and obesity. According to WHO, a WC of $\geq 88 \mathrm{~cm}$ for women and $\geq 102 \mathrm{~cm}$ for men is associated with substantially increased metabolic risk [30]. We applied the values above this WC cut off point to classify the waist as large. Household income was classified as the income status quintile from the Ministry of Internal Affairs of Suriname in Surinamese dollars, SRD (1USD = 3.35 SRD). Because of the small amount of respondents in the fourth and fifth quintile, these two were combined in the analysis. The residential addresses were stratified to urban, rural coastal areas, and the rural interior [31]. Physical activity was classified according to WHO recommendations in groups <600 MET and $\geq 600 \mathrm{MET}$.

\section{Statistical analysis}

First, we calculated the overall and ethnic-specific prevalence of hypertension and the main risk factors. Differences in the prevalence between ethnic subgroups were assessed using the Chi-square test. The collected data were subjected to a weighting procedure so inferences could be made to the whole population. The weights used for analysis were calculated to adjust for probability of selection, non-response, and differences between the sample population and target population. The adjustment weight for sample correction was calculated per sex, 10-year age group, and, where applicable, ethnicity [24]. Second, we used several adjustment models to explore whether the observed differences in association were influenced by biological, demographic, lifestyle, or anthropometric risk factors. We tested potential interactions between Hindustani (the group with the highest prevalence of hypertension from the two largest groups) and other ethnic groups, adjusted for sex and age in relation to modifiable cardiovascular risk factors. All models were evaluated with the Hosmer and Lemeshow goodness to fit test. We used the statistical software Epi
Info 3.2 and the Statistical Packages for Social Sciences (SPSS 21.0) for analyses.

\section{Results \\ Subject characteristics}

Table 1 presents the subjects' characteristics of the study population overall and per ethnic subgroup. Amerindians and Maroons had the lowest percentages of male participants and smokers and the highest percentages of subjects with low education, low income, and living in rural interior areas. Also, Amerindians had the highest BMI and WC but the lowest mean systolic blood pressure. Compared to the other ethnic groups, Creoles had the highest percentages of male participants and high education and income groups. Creoles had the lowest percentage of subjects living with a partner and the highest percentages of subjects who were employed or met the required level of physical activity. Also, they had the highest mean systolic blood pressure. Creoles, Hindustani, and Javanese exhibited low levels of living in rural interior areas. Hindustani subjects had the highest mean diastolic blood pressure. Javanese had the highest median age and the highest percentages of living with a partner and smoking. Maroons had the lowest median and mean values for BMI and WC.

Table 2 shows that the mean systolic and diastolic blood pressure is higher in men and increases with age, whereas the mean BMI was higher in women and increases with age.

Table 3 shows that a higher percentage of men smoke and comply with the recommended levels of physical activity. In both sexes, smoking increased and physical activity decreased with age.

\section{Hypertension prevalence}

The estimated overall prevalence of hypertension was $26.2 \%$ (95\% confidence interval [CI] $25.1 \%-27.4 \%$ ). Fig. 1 gives the prevalence of hypertension with and without medication use in the six ethnic groups. Creole, Hindustani, and Javanese had the highest prevalence of hypertension, and Mixed and Maroons subjects had the lowest prevalence. More than $50 \%$ of participants with hypertension were not diagnosed previously and about $25 \%$ of those treated effectively and had normal values of blood pressure. The highest proportion of undiagnosed hypertension was found in Maroons. Hindustani and Amerindians had the largest proportion of subjects with hypertension who were treated effectively, and Maroons had the lowest.

\section{Ethnic differences in the prevalence of hypertension in risk factor categories}

Table 4 shows that the prevalence of hypertension was higher in men among Hindustani; for Maroons and 
Table 1 Subject characteristics, overall and by ethnic subgroup $(N=5641)$

\begin{tabular}{|c|c|c|c|c|c|c|c|}
\hline \multirow[t]{2}{*}{ Characteristics } & Overall & Amerindian & Creole & Hindustani & Javanese & Maroon & Mixed \\
\hline & $N=5641$ & $N=427$ & $N=677$ & $N=1315$ & $N=923$ & $N=1377$ & $N=817$ \\
\hline Men \% (95\% Cl) & $49.7(48.4-51)$ & $37.6(31.7-44)$ & $54.4(50.6-58.2)$ & $52.8(50.4-55.2)$ & $51.2(47.7-54.6)$ & $43.2(40.3-46.2)$ & $46.3(43.1-49.6)$ \\
\hline Age in years, median (95 \% range) & $35.0(15.0-62.0)$ & $35.0(16.0-62.0)$ & $36.0(16-62)$ & $37.0(16.0-62.0)$ & $40.0(15.0-62.2)$ & $30.0(15.0-61.0)$ & $32.0(15.0-62.0))$ \\
\hline \multicolumn{8}{|l|}{ Education \% (95 \% Cl) } \\
\hline Low & $53(51.7-54.3)$ & 78.6(73-83.5) & $37.5(33.8-41.4)$ & $54.3(51.8-56.7)$ & 53.3(49.8-56.8) & 77.3(74.7-79.8) & $34.8(31.7-38.0)$ \\
\hline Middle & $27.9(26.7-29.1)$ & $17.8(13.2-23.1)$ & 34.8(31.1-38.6) & $27.9(25.7-30.1)$ & $32(28.8-35.4)$ & $14.1(12.1-16.4)$ & $35.4(32.3-38.6)$ \\
\hline High & $19.1(18.1-20.2)$ & $3.6(1.7-6.8)$ & $27.7(24.4-31.4)$ & 17.9(16.1-19.8) & $14.7(12.4-17.4)$ & $8.5(7-10.4)$ & 29.8(26.9-32.9) \\
\hline \multicolumn{8}{|l|}{ Income \% (95 \% Cl) } \\
\hline$<$ SRD 800/month & $33.6(32-35.2)$ & $54.7(46-63)$ & 23.0(19.0-27.6) & $30.9(28.0-34.0)$ & 23.9(20.3-27.9) & $58.3(54.4-62)$ & 23.4(19.9-27.3) \\
\hline SRD 800-1499/month & $33.9(32.3-35.5)$ & $26.4(19.3-34.4)$ & $39.9(35.0-45.0)$ & $37.6(34.6-40.8)$ & $37.8(33.6-42.2)$ & $27.6(24.3-31.2)$ & $28.3(24.6-32.4)$ \\
\hline SRD 1500-2199/month & $15(13.8-16.3)$ & $7.2(3.5-12.7)$ & $16.2(12.8-20.4)$ & 17.2(14.9-19.7) & 19.4(16.1-23.2) & $7.5(5.6-9.8)$ & 16.8(13.7-20.3) \\
\hline SRD 2200/month & 17.5(16.2-18.8) & 11.7(6.7-17.9) & $20.9(17.0-25.3)$ & 14.3(12.2-16.7) & 18.9(15.6-22.6) & $6.7(5.0-8.9)$ & $31.5(27.6-35.7)$ \\
\hline \multicolumn{8}{|l|}{ Area \% (95\% Cl) } \\
\hline Urban coastal & 75.5(74.3-76.6) & $31.2(25.4-37.2)$ & 85.8(82.9-88.3) & $83.9(82-85.6)$ & $70.7(67.4-56.8)$ & $52.3(49.2-55.3)$ & 85.4(83-38) \\
\hline Rural coastal & $16.1(15.1-17)$ & $32(26.1-38)$ & $14.1(11.7-17)$ & $16.1(14.4-18)$ & $29.3(26.2-35.4)$ & $6.9(5.5-8.7)$ & 14.3(12.2-38.6) \\
\hline Rural interior & $8.5(7.8-9.2)$ & $36.9(30.9-43.2)$ & $0(0-0.7)$ & $0(0-0.3)$ & $0(0-17.4)$ & 40.8(37.9-43.8) & $0.3(0.1-32.9)$ \\
\hline Living with partner \% (95 \% Cl) & $51.7(50.4-53)$ & $66(59.7-71.7)$ & $32.3(28.8-36)$ & $60.4(58-62.7)$ & 70.7(67.4-73.8) & $40.1(37.2-43.1)$ & $44(40.8-47.2)$ \\
\hline Working or studying \% (95 \% Cl) & $69(67.8-70.2)$ & $44.3(38.2-50.8)$ & 78.7(75.4-81.6) & $67.8(65.5-70)$ & 71.9(68.7-74.9) & $58.7(55.7-61.6)$ & 77.2(74.3-79.8) \\
\hline Smoking \% (95 \% Cl) & 14.7(13.8-15.6) & $5.3(2.8-8.7)$ & $19.1(16.2-22.3)$ & $16.2(14.5-18.1)$ & $20.2(17.5-23.1)$ & $6.5(5.1-8.2)$ & $14(11.9-16.4)$ \\
\hline $\begin{array}{l}\text { Recommended physical activity \% } \\
(95 \% \mathrm{Cl})\end{array}$ & $64.3(62.9-65.6)$ & $66.3(59.1-73.1)$ & $69.6(65.7-73.3)$ & $65.4(63-67.8)$ & $60(56.3-63.5)$ & $59.2(55.9-62.5)$ & $65.6(62.2-68.8)$ \\
\hline $\begin{array}{l}\text { Body mass index, } \mathrm{kg} / \mathrm{m}^{2}, \text { median } \\
\text { ( } 95 \% \text { range) }\end{array}$ & $25.7(25.6-25.9)$ & $26.7(18.4-40.7)$ & $25.5(17.6-41.0)$ & $26.3(17.1-39.1)$ & $26.1(17.8-40.1)$ & $24.9(17.5-41.3)$ & $25.8(17.2-39.8)$ \\
\hline $\begin{array}{l}\text { Waist circumference, } \mathrm{cm} \text {, } \\
\text { mean (SD) }\end{array}$ & $87.3(15.6)$ & $90.0(14.4)$ & $88.2(16.3)$ & $89.4(15.7)$ & $86.0(14.9)$ & $84.6(15.0)$ & $86.4(16.0)$ \\
\hline $\begin{array}{l}\text { Systolic blood pressure, } \mathrm{mmHg} \text {, } \\
\text { mean (SD) }\end{array}$ & 119.0(19.3) & 117.3(18.6) & $122.4(19.7)$ & 119.1(19.3) & 119.3(19.5) & 118.4(18.9) & 117.5(19.5) \\
\hline $\begin{array}{l}\text { Diastolic blood pressure, } \mathrm{mmHg} \text {, } \\
\text { mean (SD) }\end{array}$ & $78.6(12.7)$ & $76.3(11.4)$ & 79.4(13.2) & $79.6(12.3)$ & $79.4(13.0)$ & $77.3(13.2)$ & $77.4(12.2)$ \\
\hline
\end{tabular}

The values are estimated means (standard deviation, SD), medians (range) or proportions (confidence interval, $\mathrm{Cl}$ ) and are based on weighted data. The sample weights included population adjustment weights for sex and age. For analysis on the overall population, additional adjustment weights for ethnicity were included. The sample of the overall population included the presented ethnic subgroups $(n=5536)$ plus other unspecified ethnicities ( $n=105)$

Javanese the prevalence was higher in women. The prevalence of hypertension increased with age in all ethnic groups. For demographic risk factors, among all ethnic groups except Amerindians, the prevalence of hypertension in participants living with a partner was higher compared to single participants. Residential area was only associated with the prevalence of hypertension in Maroons. The prevalence of hypertension differed according to educational level among Maroons and Hindustani. When analyzing the influence of income, the prevalence of hypertension increased for higher incomes in Creoles, whereas it decreased for lower incomes among Hindustanis. This table shows that among Hindustani the smokers, and those with physical activity less than 600 MET per week had a higher prevalence of hypertension. This corresponds with Creole subjects who smoked and Maroon subjects who performed less than 600 MET of physical activity per week. For anthropometric risk factors, we observed that the prevalence of hypertension increased with BMI for all ethnicities except for Amerindians. For all ethnic groups, the prevalence of hypertension was higher in those with a larger WC.

\section{Ethnic differences between the odds ratios of hypertension}

Table 5 shows that in the model adjusted for age and sex only, Amerindians had a lower odds ratio (OR) for hypertension compared to Hindustani (OR: 0.7 [95 \% CI 0.6-1.0]). Adding demographic factors in model 2 further reduced the odds of hypertension in Amerindians (OR: 0.5 [95 \% CI 0.4-0.8]) and also showed a weaker association in Javanese (OR: 0.8 [95 \% CI 0.1-1.0]). In model 3, the difference between the OR for Hindustani 
Table 2 Mean systolic and diastolic blood pressure and mean BMI by age and sex

\begin{tabular}{|c|c|c|c|c|c|c|}
\hline \multirow[t]{4}{*}{ Age group } & \multicolumn{2}{|c|}{ Systolic blood pressure } & \multicolumn{2}{|c|}{ Diastolic blood pressure } & \multicolumn{2}{|l|}{$\mathrm{BMI}$} \\
\hline & \multicolumn{2}{|l|}{ Mean \pm SD (SE) } & \multicolumn{2}{|l|}{ Mean \pm SD (SE) } & \multicolumn{2}{|l|}{ Mean \pm SD (SE) } \\
\hline & Male & Female & Male & Female & Male & Female \\
\hline & $(n=2102)$ & $(n=3524)$ & $(n=2102)$ & $(n=3522)$ & $(n=2052)$ & $(n=3302)$ \\
\hline $15-24$ years & $115.1 \pm 12.6(0.5)$ & $102.6 \pm 11.1(0.4)$ & $71.5 \pm 9.8(0.4)$ & $69.5 \pm 8.4(0.3)$ & $23.0 \pm 4.8(0.2)$ & $24.2 \pm 5.2(0.2$ \\
\hline 25-34 years & $120.3 \pm 13.0(0.5)$ & $108.5 \pm 14.4(0.5)$ & $78.3 \pm 10.6(0.4)$ & $75.2 \pm 11.8(0.4)$ & $25.7 \pm 5.2(0.2)$ & $27.9 \pm 5.9(0.2$ \\
\hline $35-44$ years & $123.5 \pm 15.6(0.6)$ & $117.4 \pm 18.4(0.8)$ & $82.3 \pm 11.5(0.5)$ & $81.2 \pm 12.9(0.5)$ & $26.5 \pm 5.2(0.2)$ & $29.1 \pm 6.1(0.3)$ \\
\hline $45-54$ years & $128.5 \pm 19.0(0.8)$ & $126.3 \pm 20.6(0.9)$ & $84.3 \pm 12.5(0.5)$ & $83.6 \pm 12.2(0.5)$ & $26.1 \pm 5.1(0.2)$ & $29.2 \pm 5.8(0.3$ \\
\hline $55-64$ years & $137.9 \pm 23.6(1.4)$ & $134.6 \pm 22.0(1.2)$ & $86.6 \pm 13.4(0.8)$ & $84.3 \pm 12.3(0.7)$ & $26.2 \pm 5.2(0.3)$ & $29.7 \pm 6.3(0.3)$ \\
\hline Total pop. & $123.1 \pm 17.5(0.3)$ & $115.2 \pm 20.1(0.4)$ & $79.4 \pm 12.5(0.2)$ & $77.5 \pm 12.8(0.2)$ & $25.3 \pm 5.2(0.1)$ & $27.7 \pm 6.2(0.1)$ \\
\hline
\end{tabular}

The values are estimated means \pm the standard deviation (SD) with the standard error (SE) and are based on weighted data. Total pop. $=$ total population

and Amerindians was no longer significant, although the value for the OR remained 0.7. Thus, no material changes in associations with hypertension were observed between ethnicities after additional adjustment for lifestyle and anthropometric factors (models 3 and 4).

\section{Discussion}

In this study, the prevalence of hypertension overall and in risk factor subgroups was assessed in the six major ethnic groups of Suriname. The estimated prevalence of hypertension was above $25 \%$. The highest prevalence was found in Creoles, Hindustani, and Javanese. Half of all hypertensive participants were not diagnosed previously and a quarter were treated effectively. We observed differences in the prevalence of hypertension between ethnic subgroups with biological, demographic, lifestyle, and anthropometric risk factors and variation in the association of ethnic groups with hypertension. The major difference in association of ethnic groups with hypertension was between Hindustani and Amerindians.

\section{Prevalence}

The estimated prevalence of hypertension in our study is in line with previous reports from countries of the Caribbean, Latin America, and developing countries, which describe a prevalence of hypertension between
$16 \%$ and $35 \%$ [4, 32-37]. Most studies in western countries indicate higher prevalences of hypertension in African descendants, followed by Asian descendants, Hispanics, and Caucasians [8, 12, 38-40]. In addition, studies in Amerindians report low prevalences of hypertension [41-43]. The results of our study concur with the literature for all ethnicities except for Maroons. Previous studies suggest that differences in prevalence of hypertension among adults of African descent are caused by demographic, lifestyle, and anthropometric factors [44-46]. This is supported by our results, as the ethnic groups with the highest prevalence of hypertension (Creoles) and the lowest prevalence (Maroons), are both from African descent and have similar biological characteristics.

\section{Awareness and treatment}

In this study, awareness in hypertensive participants falls within the range of other developing countries, but the proportion of adequately treated subjects is higher. In other developing countries, it has been estimated that between $23 \%$ and $71 \%$ of all hypertensive people were aware of their condition and $4 \%$ to $16 \%$ were adequately treated [4, 47]. Success rates may be high in Suriname compared to other developing countries $[4,48]$, because of the country's extensive primary

Table 3 Prevalence of smoking and weekly required physical activity by age and sex

\begin{tabular}{|c|c|c|c|c|}
\hline \multirow[t]{4}{*}{ Age group } & \multicolumn{2}{|l|}{ Smoking } & \multicolumn{2}{|c|}{ Recommended physical activity } \\
\hline & \multicolumn{2}{|l|}{$\%(C l 95 \%)$} & \multicolumn{2}{|l|}{$\%(C \mid 95 \%)$} \\
\hline & Male & Female & Male & Female \\
\hline & $(n=2093)$ & $(n=3533)$ & $(n=1784)$ & $(n=3070)$ \\
\hline $15-24$ years & $8.8(6.9-11.2)$ & $0.6(0.2-1.5)$ & $82.2(78.9-85.2)$ & $61.9(58.0-65.7)$ \\
\hline $25-34$ years & 23.1(20.0-26.6) & $3.8(2.6-5.6)$ & $75.5(71.6-79.0)$ & $55.8(51.7-59.9)$ \\
\hline $35-44$ years & 28.9(25.3-328) & 5.6(3.9-7.9) & $68.7(64.4-72.8)$ & $57.0(52.6-61.4)$ \\
\hline $45-54$ years & $35.9(31.8-40.2)$ & $7.5(5.5-10.2)$ & $66.0(61.4-70.3)$ & $55.8(51.2-60.3)$ \\
\hline $55-64$ years & $33.6(28.1-39.4)$ & $5.8(3.7-9.1)$ & $50.6(43.3-57.1)$ & $49.5(43.7-55.5)$ \\
\hline Total pop. & $24.4(22.8-26.0)$ & $4.3(3.6-5.1)$ & $71.3(69.4-73.2)$ & $56.9(54.9-58.9)$ \\
\hline
\end{tabular}

The values are estimated proportions (95\% confidence interval $[\mathrm{CI}])$ and are based on weighted data. Total pop=total population 


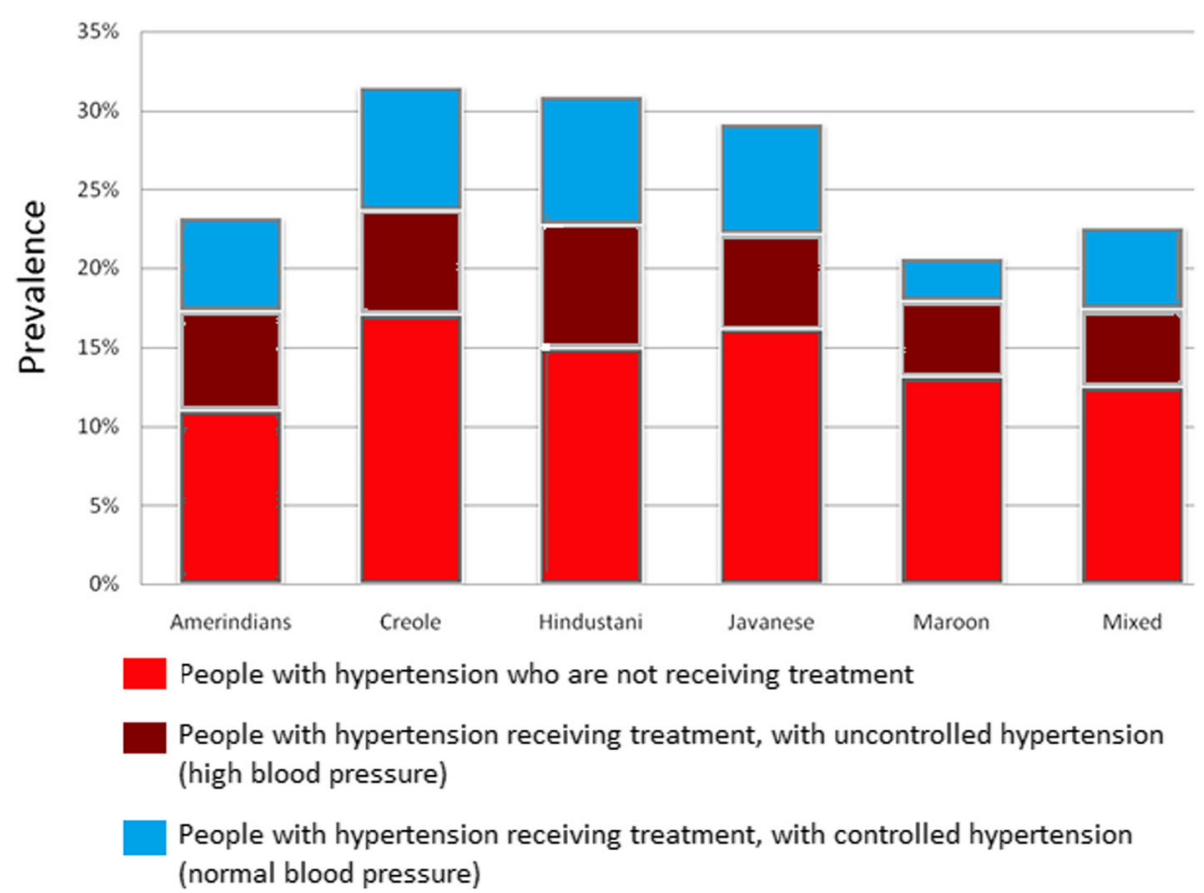

Fig. 1 The prevalence of people with hypertension per ethnic group, presented in groups not treated or treated with uncontrolled and controlled hypertension

health care system [49]. However, awareness and the ratio of effectively treated patients is higher in developed countries. In the United States, just over $80 \%$ of hypertensive subjects were aware of their condition and slightly more than $50 \%$ were treated effectively [50]. Besides dissimilar resources between developed and developing countries, there are also differences in ethnic composition. Thus, in addition to the differences in compliance with treatment and availability of medication, different responses to antihypertensive treatment by ethnic groups should also be considered to explain discrepancies in the efficacy of treatment [20]. This argument is supported by Amerindians having the highest levels of effective treatment and Maroon subjects having the lowest. Therefore, ethnic-specific treatment for hypertension may be indicated and should be explored further. The findings of this study indicate that more effort must be taken to improve awareness by people with hypertension and efficacy of treatment.

\section{Risk factors}

As in previous studies, the results in our study for sexspecific prevalence are ambiguous [51, 52]. We observed a higher prevalence of hypertension for men among Hindustani subjects and for women in Maroons and Javanese. The findings of our study in regards to age are also in line with the literature, as hypertension increases with age regardless of race and ethnicity [53]. However, the age- and sex-adjusted risk for hypertension was equal for all ethnicities, with exception of the Amerindians for whom the risk was lower. Biological mechanisms that explain higher blood pressure levels in people of African descent are described in the literature, but to our knowledge, mechanisms explaining lower blood pressure levels in Amerindians are not known and need to be studied in more depth. Neither age nor sex are modifiable risk factors. However, they may be relevant for identification of groups at risk.

Demographic factors like education, income, employment, and area of residence have been associated with hypertension [54-60]. In this study, the prevalence of hypertension increased with income in Creoles, living in the rural interior in Maroons, and living with a partner in Hindustani, Javanese, and Maroons. Prevalence decreased with education in Hindustani and Maroons, with employment in Hindustani, Javanese, and Maroons, and with level of income in the Hindustani. After adjusting for all risk factors, we measured a weaker association of Javanese and Amerindians with hypertension compared to Hindustani, which might indicate that some of these factors influence the level of hypertension for these two ethnic groups. Previous studies report higher prevalences of hypertension in urban areas compared to rural areas [6163]. Published results on physical activity from the Steps Survey 2013 in Suriname, report the percentage of required physical activity in the rural coastal area compared to the urban area [64]. A lower percentage of required physical 
Table 4 Prevalence of hypertension in risk factor categories among six ethnic groups $(N=5641)$

\begin{tabular}{|c|c|c|c|c|c|c|}
\hline \multirow[t]{3}{*}{ Characteristics } & Amerindian & Creole & Hindustani & Javanese & Maroon & Mixed \\
\hline & $N=427$ & $N=677$ & $N=1315$ & $N=923$ & $N=1377$ & $N=817$ \\
\hline & Prev(Cl 95 \%) & $\operatorname{Prev}(\mathrm{Cl} 95 \%)$ & $\operatorname{Prev}(\mathrm{Cl} 95 \%)$ & $\operatorname{Prev}(\mathrm{Cl} 95 \%)$ & Prev(Cl 95 \%) & $\operatorname{Prev}(\mathrm{Cl} 95 \%)$ \\
\hline \multicolumn{7}{|l|}{ Sex } \\
\hline Male & $27.5 \%(18.8 \%-37.6 \%)$ & $28.7 \%$ (24.2 \% - $33.6 \%)$ & $33.5 \%(30.4 \%-36.7 \%)$ & $25.7 \%(21.7 \%-30.2 \%)$ & $17.3 \%(14.0 \%-21.1 \%)$ & $23.0 \%(19.2 \%-27.2 \%)$ \\
\hline \multirow[t]{2}{*}{ Female } & $19.5 \%(13.8 \%-26.8 \%)$ & $33.9 \%(28.7 \%-39.5 \%)$ & $27.4 \%(24.4 \%-30.7 \%)$ & $32.5 \%(28.0 \%-37.3 \%)$ & $23.4 \%(20.2 \%-27.0 \%)$ & $21.2 \%(17.7 \%-25.0 \%)$ \\
\hline & $p=0.161$ & $p=0.143$ & $p<0.006$ & $p<0.030$ & $p<0.014$ & $p<0.509$ \\
\hline \multicolumn{7}{|l|}{ Age group (years) } \\
\hline $15-24.9$ & $9.0 \%(3.8 \%-18.2 \%)$ & $9.0 \%(5.2 \%-14.7 \%) a$ & $4.7 \%(2.8 \%-7.6 \%) a$ & $5.2 \%(2.2 \%-9.9 \%) a$ & $5.2 \%(3.2 \%-8.3 \%)$ & $5.2 \%(3.1 \%-8.5 \%)$ a \\
\hline $25-34.9$ & $13.0 \%(4.7 \%-25.0 \%)$ & $13.4 \%(8.5 \%-20.1 \%) a, b$ & $20.6 \%(16.8 \%-25.0 \%)$ a & $13.9 \%(8.6 \%-20.1 \%) b$ & $12.2 \%(9.0 \%-16.3 \%)$ & $14.9 \%(10.5 \%-20.4 \%) b$ \\
\hline $35-44.9$ & $25.5 \%(14.8 \%-39.2 \%)$ & $32.9 \%(24.9 \%-41.7 \%) b, c$ & $24.4 \%(20.1 \%-29.2 \%) b$ & $31.6 \%(25.3 \%-38.1 \%) c$ & $30.1 \%(24.0 \%-37.1 \%)$ & $28.0 \%(21.6 \%-34.9 \%) c$ \\
\hline $45-54.9$ & $38.8 \%(24.9 \%-54.3 \%)$ & $47.6 \%(39.3 \%-56.3 \%) c$ & $48.1 \%(43.1 \%-53.2 \%) c$ & $44.3 \%(37.1 \%-51.6 \%) d$ & $43.6 \%(35.1 \%-52.8 \%)$ & $36.5 \%(29.0 \%-44.9 \%) c$ \\
\hline \multirow[t]{2}{*}{$55-64.9$} & $43.6 \%(25.4 \%-64.6 \%)$ & $67.3 \%(57.0 \%-76.2 \%) c$ & $73.3 \%(66.6 \%-79.3 \%) d$ & $52.6 \%(42.9 \%-62.5 \%) d$ & $60.1 \%(48.7 \%$ - $70.7 \%)$ & $60.3 \%(49.3 \%-70.6 \%) \mathrm{c}$ \\
\hline & $p<0.001$ & $p<0.001$ & $p<0.001$ & $p<0.001$ & $p<0.001$ & $p<0.001$ \\
\hline \multicolumn{7}{|l|}{ Living with a partner } \\
\hline No & $21.8 \%(13.9 \%-32.3 \%)$ & $27.1 \%(23.1 \%-31.5 \%)$ & $22.5 \%(19.4 \%-25.9 \%)$ & $23.0 \%(17.8 \%-28.8 \%)$ & $17.1 \%(14.3 \%-20.3 \%)$ & $17.7 \%(14.5 \%-21.3 \%)$ \\
\hline \multirow[t]{2}{*}{ Yes } & $22.9 \%(16.7 \%-30.0 \%)$ & $39.1 \%(32.6 \%-46.0 \%)$ & $36.2 \%(33.2 \%-39.2 \%)$ & $31.4 \%(27.7 \%-35.4 \%)$ & $26.3 \%(22.2 \%-30.8 \%)$ & $27.4 \%(23.2 \%-32.1 \%)$ \\
\hline & $p<0.161$ & $p<0.143$ & $p<0.006$ & $p<0.05$ & $p<0.05$ & $p<0.509$ \\
\hline \multicolumn{7}{|l|}{ Geographic area } \\
\hline Urban area & $22.7 \%(14.2 \%-33.7 \%)$ & $30.5 \%(26.8 \%-34.4 \%)$ & $29.8 \%(27.5 \%-32.3 \%)$ & $28.1 \%(24.6 \%-32.0 \%)$ & $16.3 \%$ (13.4 \% - $19.7 \%)$ a & $21.6 \%(18.8 \%-24.6 \%)$ \\
\hline Rural coastal area & $24.6 \%(15.8 \%-35.6 \%)$ & $34.6 \%(24.9 \%-44.7 \%)$ & $34.8 \%(29.1 \%-40.7 \%)$ & $31.1 \%(25.3 \%-37.3 \%)$ & $20.6 \%(12.6 \%-32.0 \%) a, b$ & $24.8 \%(18.0 \%-33.2 \%)$ \\
\hline \multirow[t]{2}{*}{ Rural interior } & $20.5 \%(12.8 \%-30.1 \%)$ & N/A & N/A & N/A & $26.5 \%(22.5 \%-30.9 \%) b$ & N/A \\
\hline & $p<0.797$ & $p=0.446$ & $p=0.113$ & $p=0.390$ & $p<0.001$ & $p=0.373$ \\
\hline \multicolumn{7}{|l|}{ Schooling } \\
\hline Primary & $23.7 \%(17.9 \%-30.2 \%)$ & $30.1 \%(24.3 \%-36.2 \%)$ & $35.7 \%(32.6 \%-39.0 \%)$ & $31.2 \%(26.9 \%-35.9 \%)$ & $23.2 \%(20.4 \%-26.2 \%)$ & $21.9 \%(17.6 \%-27.0 \%)$ \\
\hline Secondary & $21.8 \%(11.3 \%-37.4 \%)$ & $34.3 \%(28.0 \%-40.8 \%)$ & $27.4 \%(23.4 \%-31.8 \%)$ & $28.1 \%(22.8 \%-34.1 \%)$ & $11.6 \%(6.7 \%-17.5 \%)$ & $21.0 \%(16.8 \%-26.0 \%)$ \\
\hline \multirow[t]{2}{*}{ Higher } & $2.6 \%(2.1 \%-34.6 \%)$ & $30.1 \%(23.5 \%-37.3 \%)$ & $18.5 \%(14.2 \%-23.4 \%)$ & $25.6 \%(18.0 \%-34.4 \%)$ & $11.6 \%(6.2 \%-20.5 \%)$ & $20.2 \%(15.5 \%-25.4 \%)$ \\
\hline & $p=0.253$ & $p=0.549$ & $p<0.001$ & $p=0.440$ & $p<0.001$ & $p=0.864$ \\
\hline \multicolumn{7}{|l|}{ Working or studying } \\
\hline Yes & $21.8 \%(15.5 \%-29.8 \%)$ & $35.8 \%(27.9 \%-44.1 \%)$ & $39.7 \%(35.6 \%-43.9 \%)$ & $38.1 \%(31.8 \%-44.7 \%)$ & $24.6 \%(20.8 \%-29.0 \%)$ & $26.5 \%(20.9 \%-33.1 \%)$ \\
\hline \multirow[t]{2}{*}{ No } & $23.3 \%(15.8 \%-32.2 \%)$ & $29.8 \%(26.0 \%-33.9 \%)$ & $26.4 \%(23.8 \%-29.0 \%)$ & $25.5 \%(22.0 \%-29.2 \%)$ & $18.0 \%(15.2 \%-21.3 \%)$ & $20.6 \%(17.8 \%-23.8 \%)$ \\
\hline & $P=0.816$ & $p=0.178$ & $p<0.001$ & $p<0.001$ & $p<0.008$ & $p<0.057$ \\
\hline
\end{tabular}


Table 4 Prevalence of hypertension in risk factor categories among six ethnic groups $(N=5641)$ (Continued)

Income quintile in SRD

Q2 800-1499/month

$21.5 \%(13.3 \%-32.8 \%) \quad 18.6 \%(11.5 \%-28.7 \%) a$ $32.7 \%(18.0 \%-49.9 \%)$ $21.9 \%(2.5 \%-55.8 \%)$

Q 3 1500-2199/month $18.9(4.0 \%-45.0 \%)$

$$
p=0.732
$$

$27.4 \%(20.4 \%-35.1 \%) a, b$ $40.3 \%(27.9 \%-53.3 \%) b, c$ $42.2 \%(31.2 \%-53.7 \%) c$ $p<0.003$

$23.1 \%(17.9 \%-28.9 \%) \quad 29.0 \%(25.3 \%-33.1 \%)$ $12.1 \%(1.8 \%-43.6 \%) \quad 39.1 \%(30.7 \%-48.1 \%)$ $p=0.443$ $p<0.023$

Physical activity $<600$ MET $\geq 600 \mathrm{MET}$

Body mass index

$<23$

$23-24.9$

$25-27.5$

27.5-30

$\geq 30$

Waist circumference

Normal

High
$29.0 \%(17.9 \%-41.4 \%) \quad 34.8 \%(27.9 \%-42.4 \%)$ $18.8 \%(12.2 \%-26.6 \%) \quad 29.5 \%(25.1 \%-34.2 \%)$ $p=0.75$ $p=0.354$

$18.4 \%(9.1 \%-33.0 \%) \quad 12.4 \%(8.2 \%-17.6 \%) a$ $20.4 \%(10.5 \%-35.1 \%) \quad 17.9 \%(10.6 \%-26.6 \%) a$ $17.3 \%(7.0 \%-31.6 \%) \quad 41.1 \%(30.4 \%-52.1 \%) b$ $14.0 \%(5.6 \%-29.4 \%) \quad 49.7 \%(38.3 \%-61.0 \%) b$ $33.8 \%(22.8 \%-45.6 \%) \quad 44.8 \%(37.6 \%-52.3 \%) b$ $p=0.111$ $p<0.001$

$18.3 \%(12.6 \%-25.8 \%) \quad 24.6 \%(20.6 \%-29.0 \%)$ $30.8 \%(21.5 \%-40.9 \%) \quad 46.3 \%(39.7 \%-53.3 \%)$ $p<0.001$ $p<0.001$
$33.9 \%(28.6 \%-39.6 \%) \quad 26.9 \%(19.4 \%-35.9 \%)$ $33.0 \%(28.3 \%-38.2 \%)$ $29.1 \%(22.3 \%-36.7 \%)$ $19.7 \%(13.4 \%-27.3 \%)$ $p<0.03$

$28.8 \%(26.5 \%-31.3 \%)$ $40.0 \%(34.1 \%-45.9 \%)$ $p<0.001$

$40.4 \%(36.1 \%-44.7 \%)$ $26.1 \%(23.4 \%-28.9 \%)$ $p<0.001$

$14.3 \%(11.3 \%-18.0 \%)$ $29.4 \%(23.1 \%-35.9 \%)$ $31.8 \%(26.6 \%-37.4 \%)$ $39.1 \%(33.0 \%-45.4 \%)$ $44.2 \%(39.4 \%-49.2 \%) a$ $p<0.001$

$21.7 \%(19.2 \%-24.3 \%)$ $46.4 \%(42.3 \%-50.5 \%)$ $p<0.001$
$27.8 \%(21.8 \%-34.9 \%)$ $29.1 \%(20.5 \%-39.2 \%)$ $29.7 \%(21.1 \%-40.2 \%)$ $p=0.965$

$29.5 \%(26.0 \%-33.1 \%)$ $27.3 \%(20.5 \%-34.6 \%)$ $p=0.547$

$28.8 \%(23.7 \%-34.2 \%)$ $28.4 \%(24.3 \%-32.8 \%)$ $p=0.775$

$8.7 \%(5.5 \%-13.4 \%)$ $22.9 \%(15.3 \%-31.7 \%)$ $35.3 \%(27.5 \%-43.8 \%)$ $36.6 \%(28.1 \%-45.3 \%) a, b$ $46.1 \%(38.9 \%-53.3 \%) b$ $p<0.001$

$21.6 \%(18.3 \%-25.2 \%)$ $49.2 \%(42.5 \%-56.1 \%)$ $p<0.001$
$24.7 \%(20.6 \%-29.4 \%)$ $22.0 \%(16.4 \%-28.9 \%)$ $26.8 \%(14.8 \%-40.7 \%)$ $16.7 \%(6.6 \%-30.0 \%)$ $p=0.558$

$20.8 \%(18.4 \%-23.5 \%)$ $20.6 \%(11.4 \%-31.4 \%)$ $p=0.865$

$23.9 \%(19.7 \%-28.7 \%)$ $18.2 \%(15.1 \%-21.8 \%)$ $p<0.05$

$11.3 \%(8.4 \%-15.0 \%)$ a $9.5 \%(5.2 \%-15.2 \%) a$ $23.3 \%(16.8 \%-30.9 \%) b$ $24.4 \%(17.0 \%-32.7 \%) b$ $39.4 \%(33.2 \%-45.7 \%)$ $p<0.001$

$12.6 \%(10.3 \%-15.3 \%)$ $39.1 \%(33.6 \%-44.7 \%)$ $p<0.001$
$22.1 \%(14.9 \%-20.2 \%)$ $30.9 \%(23.5 \%-38.8 \%)$ $20.4 \%(12.5 \%-30.2 \%)$ $25.8 \%(19.4 \%-33.2 \%)$ $p=0.467$

$20.0 \%(17.4 \%-23.0 \%)$ $34.0 \%(26.0 \%-42.7 \%)$ $p<0.001$

$23.4 \%(18.6 \%-28.7 \%)$ $21.3 \%(18.0 \%-25.0 \%)$ $p=0.417$

$9.8 \%(6.5 \%-13.7 \%)$ a $12.5 \%(7.4 \%-19.0 \%) a$ $21.3 \%(15.1 \%-29.1 \%) b$ $29.0 \%(21.1 \%-37.9 \%) b$ $40.1 \%(33.7 \%-46.7 \%)$ $p<0.001$

$15.4 \%(12.7 \%-18.5 \%)$ $40.2 \%(34.1 \%-46.4 \%)$ $p=0.033$

The values are estimated proportions (with confidence interval in parentheses) and are based on data weighted for sample correction including population adjustment weights for sex and age. Pearson chi-square tests were calculated for the differences between prevalence in the subset of categories of the risk factors per ethnic group. Each subscript letter (a, b c...) denotes a subset of categories with column proportions that do not differ significantly from each other at the .05 level. N/A indicates not applicable 
Table 5 Adjusted risk of hypertension between ethnic groups

\begin{tabular}{|c|c|c|c|c|}
\hline & Model 1 & Model 2 & Model 3 & Model 4 \\
\hline & $\mathrm{OR}(\mathrm{Cl})$ & $\mathrm{OR}(\mathrm{Cl})$ & $\mathrm{OR}(\mathrm{Cl})$ & $\mathrm{OR}(\mathrm{Cl})$ \\
\hline Hindustani & 1 & 1 & 1 & 1 \\
\hline Creole & $1.0(0.8-1.2)$ & $1.0(0.7-1.3)$ & $1.0(0.8-1.2)$ & $1.0(0.8-1.3)$ \\
\hline Javanese & $0.9(0.7-1.1)$ & $0.8(0.1-1.0)^{*}$ & $0.9(0.7-1.1)$ & $1.0(0.8-1.2)$ \\
\hline Mixed & $0.8(0.7-1.0)$ & $0.9(0.7-1.2)$ & $0.8(0.6-1.0)$ & $0.9(0.7-1.1)$ \\
\hline aroon & $0.9(0.7-1.0)$ & $0.9(0.6-1.2)$ & $0.8(0.7-1.0)$ & $0.8(0.7-1.0)$ \\
\hline Amerindian & $0.7(0.6-1)^{*}$ & $0.5(0.4-0.8)^{*}$ & $0.7(0.5-1.0)$ & $0.7(0.5-0.9)^{*}$ \\
\hline
\end{tabular}

${ }^{*} P<0.05$

Model 1 is the basic multivariate model adjusted for sex and age

Model 2 is adjusted for variables in model 1 plus demographic factors like

living area, marital status, education, income, and working status

Model 3 is adjusted for variables in model 1 plus lifestyle factors like smoking

and physical activity

Model 4 is adjusted for variables in model 1 plus anthropometric measures

like body mass index and waist circumference

activity could be associated with the higher prevalence of hypertension measured in the rural coastal area in our study. Possibly, our observations in this study of Maroons having higher levels of employment, higher levels of education, and lower prevalences of hypertension, are related to the fact that they are more likely to live in urban areas. In such a case, it is plausible that these factors have an impact on the prevalence of hypertension in the urban setting. However, no previous studies have compared hypertension in urban and rural settings in Suriname, and the higher prevalence observed in Maroons living in rural coastal and rural interior areas requires further research.

The results clearly demonstrate that the prevalence of hypertension in demographic risk factor subgroups differed between ethnic groups. We also observed a change in the different associations of ethnic groups with hypertension after adjusting for demographic factors. These results imply that achievement of uniform intervention programs will be limited and tailor-made programs should be developed.

For lifestyle factors, the prevalence of hypertension was higher in Hindustani and Creole smokers, and in Maroon and Hindustani subjects performing less than 600 MET of physical activity per week. Previous studies show that lifestyle factors like low physical activity and cigarette smoking are associated with hypertension [65-68]. These risk factors are modifiable and are valuable points of interest for intervention programs.

Many studies show that high BMI or WC are risk factors of hypertension [69-71]. In this study, the prevalence of hypertension increased with BMI and WC categories for all ethnicities. The BMI subgroups for Amerindians, however, were too small to show significant differences at a 0.05 level, thus the increase with BMI categories for this group could not be tested for statistical significance. Adjustment for these anthropometric factors in addition to sex and age did not affect the association with hypertension, and the OR remained lower in Amerindians. The results suggest that public health interventions focusing on both BMI and WC control should not be aimed at specific ethnic groups; however, in order to confirm this suggestion, this association should be explored in additional studies.

The major difference in association of ethnic groups with hypertension was between Hindustani and Amerindians. Differences in associations of ethnic groups with hypertension were not materially affected by adjustment for lifestyle factors or anthropometric factors. The differences in associations of the ethnic groups with hypertension were mostly influenced by demographic risk factors, and these should be addressed accordingly.

\section{Strength and limitations}

Strengths of this cross-sectional study include the design, with a stratified multistage cluster and a large sample size, which was adequate to represent the ethnic and geographic diversity of the Surinamese population by sex in five different age groups [24]. The design included measures like the Kish method and standardized data collection tools to minimize selection and interviewer bias [24, 27]. In addition, in the analysis, sample weights were applied to correct for selection bias. Further, the percentages of missing data in general were relatively small (1.1\%), except for income status (30.2\%). However, the model that included income as a confounder fit and was not compromised (goodness to fit test). Still, some limitations should be considered regarding this study. First, despite the overall large sample size of the study some risk factors were present in only a few participants when analyzed per ethnic subgroup. In these cases, the sample size was too small to measure statistical differences between the observed hypertension rates at a significance level of 0.05 . Second, although the wide range of variables evaluated in this study allowed us to control for confounders, residual confounding might still have occurred, as with any observational study. For example, information on nutrition was not considered in this paper.

\section{Conclusion}

The results of the present study showed that the prevalence of hypertension in Suriname was in the range of developing countries. By ethnic group, the highest prevalence was found in Creoles and the lowest in Maroons. Next to Creoles, Hindustani and Javanese also had high prevalences of hypertension, and Amerindians exhibited a low prevalence, after Maroons. In the analysis, Amerindians had the lowest OR for hypertension, in comparison to Hindustani. The differences observed in the prevalence of hypertension for risk factor subgroups between and within ethnic groups allow us to generate valuable ethnic-specific hypotheses, which are important for research on the development of tailor-made public health interventions. 


\section{Abbreviations}

BMI: Body mass index; GPAQ: Global Physical Activity Questionnaire; MET: Metabolic Equivalent of Task; NCD: Non-communicable disease; PAHO: Pan American Health Organization; WC: Waist circumference; WHO: World Health Organization

\section{Acknowledgments}

This study was conducted by the Faculty of Medical Sciences of the Anton de Kom University of Suriname in close collaboration with the Ministry of Health and the Pan American Health Organization (PAHO). We acknowledge the participation of all the respondents and the support of all the personnel in this study. We especially thank Christel Smits from the department of Public Health, Faculty of Medical Sciences, Anton de Kom University of Suriname for her participation in the coordination team and her assistance with data collection and control. We also thank Albert Hofman, from the department of Epidemiology, Erasmus MC, University Medical Center, Rotterdam, the Netherlands, for supervision on the realization of this study.

\section{Funding}

The research was funded by the Ministry of Health, Republic of Suriname $\mathrm{MOH} / \mathrm{NCD} / 1214 / \mathrm{GOS}$. The funding of the Ministry covered the operational costs.

\section{Availability of data and supporting materials}

All authors have access to the data. Reviewers only have access to the data for testing and are required to sign a confidentiality agreement.

\section{Authors' contributions}

ISKK participated in the design of the study, data collection, statistical analysis, interpretation of data, and drafting the manuscript. WWJ collaborated in the design of the study, statistical analysis, interpretation of data, and drafting the manuscript. LMN collaborated with the interpretation of data and drafting the manuscript. JRT collaborated in the design of the study, data collection, interpretation of data, and drafting the manuscript. All authors read and approved the final manuscript.

\section{Competing interests}

The authors declare that they have no competing interests.

\section{Ethics approval and consent to participate}

The Ethics Committee of the Ministry of Health in Suriname (Commissie mensgebonden wetenschappelijk onderzoek (ref: VG 004-2013)) approved this research.

Each study participant was first informed about the details of the study and then asked to sign for consent. Apart from the aims and the survey procedures, the respondent received details on how the information gathered would be used. The respondent was also informed that he or she could refuse to participate in any part of the study.

\section{Author details}

'Department of Public Health, Faculty of Medical Sciences, Anton de Kom University of Suriname, Paramaribo, Suriname. ${ }^{2}$ Department of Physiology, Faculty of Medical Sciences, Anton de Kom University of Suriname, Paramaribo, Suriname. ${ }^{3}$ Department of Epidemiology, Erasmus MC, University Medical Center, Rotterdam, The Netherlands. ${ }^{4}$ Department of Pediatrics, Erasmus MC, University Medical Center, Rotterdam, The Netherlands.

Received: 27 August 2015 Accepted: 9 September 2016 Published online: 17 September 2016

\section{References}

1. Bromfield S, Muntner P. High blood pressure: the leading global burden of disease risk factor and the need for worldwide prevention programs. Curr Hypertens Rep. 2013; doi:10.1007/s11906-013-0340-9.

2. Santulli G. Epidemiology of cardiovascular disease in the 21 st Century: updated numbers and updated facts. J Cardiovasc Dis. 2013;1(1):1-2.

3. The Association of Physiscians in India. Epidemiology of hypertension. In JAPI. 2013. http://www.japi.org/february_2013_special_issue_hypertension_ guidelines/06_epidemiology_of_hypertension.pdf. Accessed 2 Apr 2015.

4. Ibrahim MM, Damasceno A. Hypertension in developing countries. Lancet. 2012; doi:10.1016/s0140-6736(12)60861-7.
5. Agyemang C, Kieft S, Snijder MB, Beune EJ, van den Born BJ, Brewster LM et al. Hypertension control in a large multi-ethnic cohort in Amsterdam, The Netherlands: The HELIUS study. Int J Cardiol. 2015; doi:10.1016/j.ijcard.2015.01.061.

6. Agyemang C, de-Graft Aikins A, Bhopal R. Ethnicity and cardiovascular health research: pushing the boundaries by including comparison populations in the countries of origin. Ethn Health. 2012; doi:10.1080/13557858.2012.730607.

7. Agyemang C, Kunst A, Bhopal R, Zaninotto P, Unwin N, Nazroo J, et al. A cross-national comparative study of blood pressure and hypertension between English and Dutch South-Asian- and African-origin populations: the role of national context. Am J Hypertens. 2010;23(6):639-48.

8. Agyemang C, van Valkengoed I, van den Born BJ, Stronks K. Prevalence and determinants of prehypertension among African Surinamese, Hindustan Surinamese, and White Dutch in Amsterdam, the Netherlands: the SUNSET study. Eur J Cardiovasc Prev Rehabil. 2007; doi:10.1097/HJR.0b013e32828621df.

9. Carson AP, Howard G, Burke GL, Shea S, Levitan EB, Muntner P. Ethnic differences in hypertension incidence among middle-aged and older adults: the multi-ethnic study of atherosclerosis. Hypertension. 2011; doi:10.1161/HYPERTENSIONAHA.110.168005

10. Holmes L, Hossain J, Ward D, Opara F. Racial/Ethnic variability in hypertension prevalence and risk factors in National Health Interview Survey. ISRN Hypertension. 2013; doi:10.5402/2013/257842.

11. Jones DW, Hall JE. Racial and ethnic differences in blood pressure: biology and sociology. Circulation. 2006; doi:10.1161/CIRCULATIONAHA.106.668731

12. Kramer H, Han C, Post W, Goff D, Diez-Roux A, Cooper R et al. Racial/ethnic differences in hypertension and hypertension treatment and control in the multi-ethnic study of atherosclerosis (MESA). Am J Hypertens. 2004 doi:10.1016/j.amjhyper.2004.06.001.

13. Tayo BO, Luke A, McKenzie CA, Kramer H, Cao G, Durazo-Arvizu R, et al. Patterns of sodium and potassium excretion and blood pressure in the African Diaspora. J Hum Hypertens. 2012;26(5):315-24.

14. Lane DA, Lip GY. Ethnic differences in hypertension and blood pressure control in the UK. QJM. 2001:94(7):391-6.

15. Martin L, Oepen J, Reinehr T, Wabitsch M, Claussnitzer G, Waldeck E et al. Ethnicity and cardiovascular risk factors: evaluation of 40,921 normal-weight, overweight or obese children and adolescents living in Central Europe. Int J Obes(Lond). 2015; doi:10.1038/ijo.2014.167.

16. Rose DE, Farmer MM, Yano EM, Washington DL. Racial/ethnic differences in cardiovascular risk factors among women veterans. J Gen Intern Med. 2013;28 Suppl 2:S524-S8.

17. Yi SS, Tabaei BP, Angell SY, Rapin A, Buck MD, Pagano WG et al. Self-blood pressure monitoring in an urban, ethnically diverse population: a randomized clinical trial utilizing the electronic health record. Circ Cardiovasc Qual Outcomes. 2015; doi:10.1161/CIRCOUTCOMES.114.000950.

18. Agyemang C, Kunst AE, Bhopal R, Zaninotto P, Unwin N, Nazroo J, et al. Hypertension in Dutch and English ethnic minorities. Blood pressure better controlled in English groups than in Dutch groups. Ned Tijdschr Geneeskd. 2011;155:A3318

19. Ayala C, Fang J, Yuan K. Prevalence of taking actions to control blood pressure among adults with self-reported hypertension in 18 States and the district of columbia, 2009. J Clin Hypertens. 2015; doi:10.1111/jch.12476.

20. Lane D, Lip GY. Blood pressure in different ethnic groups. Am J Cardiol. 2001:88(10):1218-9.

21. Punwasi W. Doodsoorzaken in Suriname 2009 - 2011 Paramaribo. Ministerie van Volksgezondheid :Bureau Openbare Gezondheidszorg. 2012.

22. Asin V. Diabetes in Suriname. In Final Report: II PAHO-DOTA Workshop on quality of diabetes care. http://www.powershow.com/view1/1067b3-Dc1Z/ Diabetes_in_Suriname_powerpoint_ppt_presentation. Accessed 31 Dec 2014.

23. Agyemang C, Oudeman E, Zijlmans W, Wendte J, Stronks K. Blood pressure and body mass index in an ethnically diverse sample of adolescents in Paramaribo, Suriname. BMC Cardiovasc Disord. 2009;9:19.

24. Krishnadath ISK, Smits CCF,Jaddoe WWV,Hofman A,Toelsie JR. Protocol of the Suriname health study: a national surveillance survey on non-communicable disease risk factors. JMIR. 2015; doi:10.2196/resprot.4205.

25. WHO. STEPwise approach to surveillance (STEPS). In: WHO. Geneva: WHO 2008. http://www.who.int/chp/steps/en/. Accessed 30 Dec 2014.

26. Algemeen Bureau voor de Statistiek, Censuskantoor. Achtste (8e) Volks- en Woningtelling in Suriname (Volume I) Demografische en Socale karakteristieken en Migratie. 2013.

27. Kish L A procedure for objective respondent selection within the household. J Am Stat Assoc. 1949;44(247):380-7. 
28. WHO. Part 3: Training and Practical Guides. In Chronic diseases and health promotion: STEPS Manual. 2008. http://www.who.int/chp/steps/manual/en/ index3.html. Accessed 30 Dec 2014.

29. Go AS, Mozaffarian D, Roger VL, Benjamin EJ, Berry JD, Blaha MJ et al. Heart disease and stroke statistics-2014 update: a report from the American Heart Association. Circulation. 2014; doi:10.1161/01.cir.0000441139.02102.80.

30. WHO expert consultation. Waist circumference and waist hip ratio. Geneva: WHO; 2008.

31. Ministry of Social Affairs and Housing, General Bureau of Statistics. Suriname Multiple Indicator Cluster Survey 2010, Final Report. Paramaribo: Ministry of Social Affairs and Housing; 2013.

32. Ministry of health education, youth, sports and culture, Cayman Islands government. WHO Steps Chronic disease risk factor survey 2012. In STEPS Country Reports. WHO http://www.who.int/chp/steps/Cayman_Islands_ NCD_RF_survey_2012.pdf. Accessed 14 June 2015.

33. Serpa Uribe H, Pena Gonzalez W, Almeida Florez O, Leon Franco MH, Ortiz Martinez RG, Hormiga Sanchez CM. Factores de riesgo para enfermedades cronicas en Santander, methodo stepwise. In STEPS Country Reports. WHO. http://www.who.int/ chp/steps/2010_STEPS_Survey_Colombia.pdf. Accessed 14 June 2015.

34. Epidemiology Unit. Ministry of Health $\mathrm{CSO}$, Ministry of Finance. WHO steps chronic disease risk factor surveillance Grenada. In STEPS Country Reports. WHO. http://www.who.int/chp/steps/Grenada_2010-11_STEPS_Report.pdf. Accessed 14 June 2015.

35. Ministerio de salud y bienestar social. Primera encuesta nacional de factores de riesgo para enfermedades no transmisibles. In STEPS Country Reports. WHO. http://www.who.int/chp/steps/2011_STEPS_Paraguay_leaflet.pdf. Accessed 14 June 2015.

36. Ministry of health Saint Lucia. Saint Lucia steps survey 2012 fact sheet. In STEPS Country Reports. WHO. http://www.who.int/chp/steps/saint_lucia/en/ Accessed 14 June 2015.

37. Ministry of health Trinidad and Tobago. Panamerican Steps chronic noncommunicable disease risk factor survey Final report. In STEPS Country Reports. WHO. http://www.who.int/chp/steps/TrinidadAndTobago_2011_ STEPS_Report.pdf. Accessed 14 June 2015.

38. Agyemang C. Ethnic Variations in Blood Pressure and Hypertension. Erasmus MC, University Medical Center Rotterdam; 2005.

39. Agyemang C, Bindraban N, Mairuhu G, Montfrans G, Koopmans R, Stronks K, et al. Prevalence, awareness, treatment, and control of hypertension among Black Surinamese, South Asian Surinamese and White Dutch in Amsterdam, The Netherlands: the SUNSET study. J Hypertens. 2005;23(11):1971-7.

40. El Fakiri F, Bruijnzeels MA, Foets MM, Hoes AW. Different distribution of cardiovascular risk factors according to ethnicity: a study in a high risk population. J Immigr Minor Health. 2008; doi:10.1007/s10903-008-9144-4.

41. Schaad JD. Epidemiological observations in Bush Negroes and Amerindians in Surinam. Trop Geogr Med. 1960;12:38-46.

42. Nelson RG, Pettitt DJ, de Courten MP, Hanson RL, Knowler WC, Bennett PH. Parental hypertension and proteinuria in Pima Indians with NIDDM. Diabetologia. 1996;39(4):433-8.

43. Sievers ML, Bennett PH, Roumain J, Nelson RG. Effect of hypertension on mortality in Pima Indians. Circulation. 1999;100(1):33-40.

44. Fuchs FD. Why do black Americans have higher prevalence of hypertension?: an enigma still unsolved. Hypertension. 2011; doi:10.1161/HYPERTENSIONAHA.110.163196.

45. Saunders E. Hypertension in African-Americans. Circulation. 1991;83(4):1465-7.

46. Cooper R, Rotimi C, Ataman S, Daniel McGee D, Osotimehin B, Kadiri S, et al. The prevelance of hypertension in seven populations of west african origin. Am J Public Health. 1997;87(2):160-8.

47. Lloyd-Sherlock P, Beard J, Minicuci N, Ebrahim S, Chatterji S. Hypertension among older adults in low- and middle-income countries: prevalence, awareness and control. Int J Epidemiol. 2014; doi:10.1093/ije/dyt215.

48. Mendis S, Abegunde D, Oladapo O, Celletti F, Nordet P. Barriers to management of cardiovascular risk in a low-resource setting using hypertension as an entry point. J Hypertens. 2004;22(1):59-64.

49. Goede H. Mapping of PHC in Suriname. In: South American Instutute of Government in health (ISAGS). 2014. http://www.isags-unasur.org/uploads/ biblioteca/7/bb[192]ling[3]anx[564].pdf.

50. Amy L, Valderrama CG. Carla Mercado, Racial/ethnic disparities in the awareness, treatment, and control of hypertension - United States, 20032010. MMWR Morb Mortal Wkly Rep. 2013;62(18):351-5.

51. Ojeda NB, Intapad S, Alexander BT. Sex differences in the developmental programming of hypertension. Acta Physiol (Oxf). 2014; doi:10.1111/apha.12206.
52. Avolio AP, Deng FQ, Li WQ, Luo YF, Huang ZD, Xing LF, et al. Effects of aging on arterial distensibility in populations with high and low prevalence of hypertension: comparison between urban and rural communities in China. Circulation. 1985;71(2):202-10.

53. McEniery CM, Wilkinson IB, Avolio AP. Age, hypertension and arterial function. Clin Exp Pharmacol Physiol. 2007; doi:10.1111/j.1440-1681.2007.04657.x.

54. Ganguli MC, Grimm Jr RH, Svendsen KH, Flack JM, Grandits GA, Elmer PJ. Higher education and income are related to a better Na:K ratio in blacks: baseline results of the Treatment of Mild Hypertension Study (TOMHS) data. Am J Hypertens. 1997;10(9 Pt 1):979-84.

55. Chaix B, Guilbert P, Chauvin P. A multilevel analysis of tobacco use and tobacco consumption levels in France: are there any combination risk groups? Eur J Public Health. 2004;14(2):186-90.

56. de Lolio CA, Pereira JC, Lotufo PA, de Souza JM. Arterial hypertension and possible risk factors. Rev Saude Publica. 1993;27(5):357-62.

57. Tobe SW, Kiss A, Szalai JP, Perkins N, Tsigoulis M, Baker B. Impact of job and marital strain on ambulatory blood pressure results from the double exposure study. Am J Hypertens. 2005; doi:10.1016/j.amjhyper.2005.03.734.

58. Schumann R, Shikora SA, Sigl JC, Kelley SD. Association of metabolic syndrome and surgical factors with pulmonary adverse events, and longitudinal mortality in bariatric surgery. Br J Anaesth. 2015; doi:10.1093/bja/aeu362.

59. Rumball-Smith J, Nandi A, Kaufman JS. Working and hypertension: gaps in employment not associated with increased risk in 13 European countries, a retrospective cohort study. BMC Public Health. 2014; doi:10.1186/1471-2458-14-536.

60. Kaczmarek M, Stawinska-Witoszynska B, Krzyzaniak A, KrzywinskaWiewiorowska M, Siwinska A. Who is at higher risk of hypertension? Socioeconomic status differences in blood pressure among Polish adolescents: a population-based ADOPOLNOR study. Eur J Pediatr. 2015; doi:10.1007/s00431-015-2554-0.

61. Ratovoson R, Rasetarinera OR, Andrianantenaina I, Rogier C, Piola P, Pacaud P. Hypertension, a neglected disease in rural and urban areas in Moramanga, Madagascar. PloS One. 2015;10(9):e0137408. doi:10.1371/journal.pone.0137408.

62. Addo J, Smeeth L, Leon DA. Hypertension in sub-saharan Africa: a systematic review. Hypertension. 2007;50(6):1012-8. doi:10.1161/HYPERTENSIONAHA.107.093336.

63. Bhadoria AS, Kasar PK, Toppo NA, Bhadoria P, Pradhan S, Kabirpanthi V. Prevalence of hypertension and associated cardiovascular risk factors in Central India. J Family Community Med. 2014;21(1):29-38. doi:10.4103/2230-8229.128775.

64. Baldew SS, Krishnadath IS, Smits CC, Toelsie JR, Vanhees L, Cornelissen V. Selfreported physical activity behavior of a multi-ethnic adult population within the urban and rural setting in Suriname. BMC Public Health. 2015;15:485. doi:10.1186/s12889-015-1807-1.

65. Hu W, Zhang T, Shi J, Qin W, Tong L, Shen Y. Association between cigarette smoking and hypertension in men: a dose response relationship analysis. Zhonghua Xin Xue Guan Bing Za Zhi. 2014;42(9):773-7.

66. D'Elia L, De Palma D, Rossi G, Strazzullo V, Russo O, lacone R et al. Not smoking is associated with lower risk of hypertension: results of the Olivetti Heart Study. Eur J Public Health. 2014; doi:10.1093/eurpub/ckt041.

67. Campbell NRC, Choi BCK, Taylor G, Wilson L, Cléroux J, George Fodor J, Leiter LA, Spence D. 1. Methods and an overview ofthe Canadian recommendations. CMAJ. 1999;160(9):S1-S8

68. Cleroux J, Feldman RD, Petrella RJ. Lifestyle modifications to prevent and control hypertension. 4. Recommendations on physical exercise training. Canadian Hypertension Society, Canadian Coalition for High Blood Pressure Prevention and Control, Laboratory Centre for Disease Control at Health Canada, Heart and Stroke Foundation of Canada. CMAJ. 1999;160(9 Suppl):S21-8.

69. Midha T, Krishna V, Nath B, Kumari R, Rao YK, Pandey U, et al. Cut-off of body mass index and waist circumference to predict hypertension in Indian adults. World J Clin Cases. 2014;2(17):272-8. doi:10.12998/wjcc.v2.i7.272.

70. Roka R, Michimi A, Macy G. Associations between hypertension and body mass index and waist circumference in U.S. Adults: a comparative analysis by gender. High Blood Press Cardiovasc Prev. 2015; doi:10.1007/s40292-015-0106-3.

71. Dong B, Wang Z, Yang Y, Wang HJ, Ma J. Intensified association between waist circumference and hypertension in abdominally overweight children. Obes Res Clin Pract. 2015; doi:10.1016/j.orcp.2015.04.002. 